\title{
The analgesic effect of ultrasound-guided transverse abdominis plane block after laparoscopic totally extraperitoneal hernia repair
}

\author{
Mun Gyu Kim, Soon Im Kim, Si Young Ok, Sang Ho Kim, Se-Jin Lee, Sun-Young Park, Su Myung Lee, \\ and Bo-Il Jung
}

Department of Anesthesiology and Pain Medicine, Soonchunhyang University Seoul Hospital, Seoul, Korea

Background: The ultrasound-guided transverse abdominis plane block (TAPB) reduces postoperative pain after laparoscopic abdominal surgery. But, its effect post laparoscopic totally extraperitoneal hernia repair (TEP) is not clear. In this study, we evaluated the analgesic effect of ultrasound-guided TAPB in TEP.

Methods: In this prospective, randomized study, forty adult patients (ASA I-II) scheduled for a TEP under general anesthesia were studied. In the TAPB group $(\mathrm{n}=20)$, an ultrasound-guided bilateral TAPB was performed with $0.375 \%$ ropivacaine $15 \mathrm{ml}$ on each side after the induction of general anesthesia. The control group $(\mathrm{n}=20)$ did not have TAPB performed. Fentanyl $50 \mu \mathrm{g}$ was repeatedly injected as per the patient's request in the recovery room. Pain scores at rest and on coughing were assessed postoperatively in the recovery room (20 $\mathrm{min}$, at discharge) and at 4, 8 , and 24 hours after surgery.

Results: In the recovery room, pain scores (numeric rating scale, $0-10$ ) at postoperative 20 min were lower in the TAPB group $(3.9 \pm 1.6,4.9 \pm 1.8)$ than the control group $(6.9 \pm 1.6,8.0 \pm 1.6)$ at rest and on coughing. Also, pain scores upon discharge from the recovery room were lower in the TAPB group $(3.2 \pm 1.2,4.2 \pm 1.5)$ than the control group (5.3 $\pm 1.6,6.5 \pm 1.8)$ at rest and on coughing.

Conclusions: The ultrasound-guided TAPB in patients that had undergone TEP reduced postoperative pain scores and the fentanyl requirement in the recovery room. Also, pain scores on coughing were reduced until postoperative 8 hours. (Korean J Anesthesiol 2012; 63: 227-232)

Key Words: Herniorrhaphy, Laparoscopy, Ropivacaine, Transverse abdominis plane block, Ultrasonography.

Received: February 17, 2012. Revised: March 21, 2012. Accepted: April 17, 2012.

Corresponding author: Soon Im Kim, M.D., Department of Anesthesiology and Pain Medicine, Soonchunhyang University Seoul Hospital, 22, Daesagwan-gil, Yongsan-gu, Seoul 140-887, Korea. Tel: 82-2-705-9294, Fax: 82-2-790-0394, E-mail: soonnim@schmc.ac.kr

(c) This is an open-access article distributed under the terms of the Creative Commons Attribution Non-Commercial License (http:// creativecommons.org/licenses/by-nc/3.0/), which permits unrestricted non-commercial use, distribution, and reproduction in any medium, provided the original work is properly cited. 


\section{Introduction}

Inguinal hernia repair is one of the most common surgeries performed by surgeons. Open and laparoscopic herniorraphy are both used, but since the evolution of surgical tools and new surgical skills in the 1990's, laparoscopic procedure have become more prevalent. There are two laparoscopic methods: laparoscopic transabdominal preperitoneal hernia repair (TAPP) and laparoscopic totally extraperitoneal hernia repair (TEP). The choice for the surgical method depends on the surgeon's skills, preference, and the patient's condition. The prevalence of laparoscopies is due to the advantage of fewer complications, decrease in hospital length of stay, speed of recovery, fast return to activities of daily living and work $[1,2]$.

Generally laparoscopic surgeries are known to be relatively less painful, but still require pain management. Many attempt at post-operative pain control following a laparoscopic cholecystectomy exist. The infiltration of local anesthetic at the trocar insertion site, into the intraperitoneal space or blood vessel by direct local anesthetic administration are effective for postoperative pain reduction [3-5]. Also the ultrasound-guided transverse abdominis plane block (TAPB) is reported to be safe to perform and to reduce perioperative and postoperative pain and reduce the dosage of opioid analgesics $[6,7]$.

In our pilot study patients in the recovery room following a TEP had a mean pain score of $7.0 \pm 1.7$ on the numeric rating scale (NRS), and one patient needed a great dosage of analgesics (up to fentanyl $200 \mu \mathrm{g}$ ). Thus post-operative pain control is deemed necessary. Since TEP is performed in a localized site in the extraperitoneal lower abdomen and somatic pain is considered to be greater than visceral pain, TAPB is considered

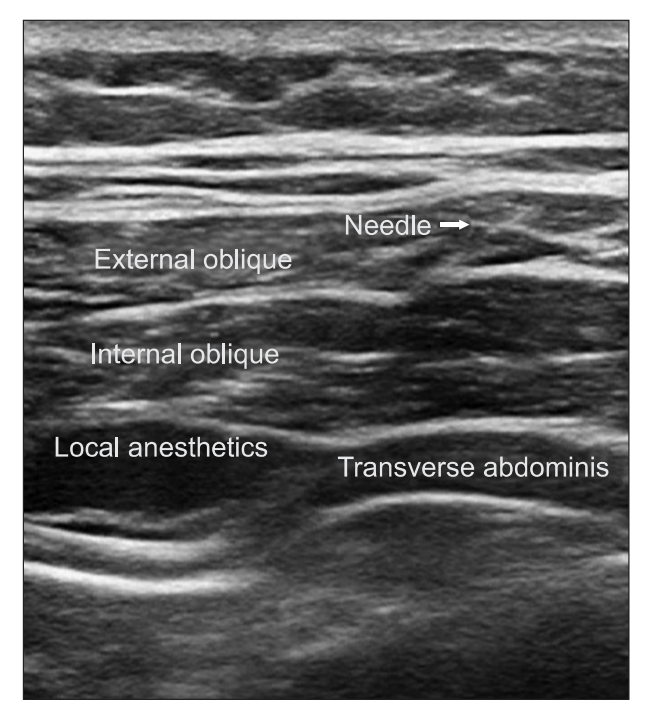

Fig. 1. Ultrasound imaging after injection of local anesthetics. to greatly help in postoperative pain control. There are very few studies focused on pain and TAPB in TEP patients. So the authors performed the present study to find the analgesic effects of ultrasound-guided TAPB's analgesic effects on TEP patients.

\section{Materials and Methods}

The present study had forty TEP patient participants (ASA I-II) aged 20 and older. We received permission from the hospital ethics committee. We explained the purpose and method of the study then received their written consent before starting the study. Patients were excluded from the study if they had a past history of hernia repair or complained of severe pain at the surgical site before the operation, or who had little understanding of the pain score.

We randomly divided patients into the TAPB group $(n=20)$ which had TAPB and the control group $(n=20)$, which did not. We gave an intramuscular injection of glycopyrrolate $0.2 \mathrm{mg}$ to all patients before surgery as premedication. Remifentanil $1 \mu \mathrm{g} /$ $\mathrm{kg}$, lidocaine $40 \mathrm{mg}$, propofol $1-2 \mathrm{mg} / \mathrm{kg}$, rocuronium $0.6 \mathrm{mg} /$ $\mathrm{kg}$ iv. was used for anesthesia induction before endotracheal intubation. We used oxygen $2 \mathrm{~L} / \mathrm{min}$, nitrous oxide $2 \mathrm{~L} / \mathrm{min}$, desflurane 4 vol\% and continuously infused remifentanil for anesthesia maintenance. During surgery, we monitored the patient with NIBP, ECG, arterial oxygen saturation, capnography, and bispectral index (BIS).

We performed TAPB after anesthesia induction using the method by Hebbard et al. [8]. With an ultrasound guide, we placed a probe immediately above the iliac crest vertical to the mid-axillary line, inserted a $22 \mathrm{G}$ blunt needle, and injected

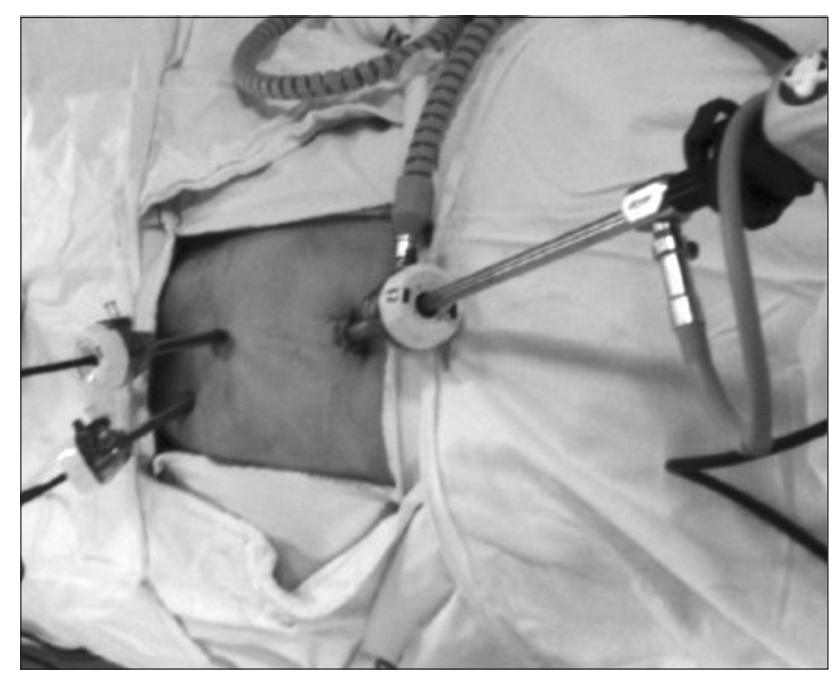

Fig. 2. Trocar sites of laparoscopic total extraperitoneal hernia repair (TEP). 
$0.375 \%$ ropivacaine $15 \mathrm{ml}$ into the transverse abdominis plane (TAP). The opposite side was performed in the same manner (Fig. 1). Also, during surgery we maintained BIS at 40-60 and and kept mean arterial pressure at $60-100 \mathrm{mmHg}$ by adjusting the remifentanil dosage. When the skin was sutured, we stopped the continuous infusion of remifentanil and recorded the dosages used.

The surgery was performed using the traditional TEP method (Fig. 2). Carbon dioxide infusion pressure was set at $12 \mathrm{mmHg}$, a mesh was placed and secured with a tacker. All surgeries were performed by the same surgeon. After surgery, glycopyrrolate and pyridostigmine used to reverse the muscle relaxants.

Upon twenty minutes after arriving in the recovery room, pain scores were taken at rest and on coughing using NRS (0: no pain, 10: greatest pain). Pain was blindly assessed and recorded before the patient was discharged from the recovery room (post-surgery 1 hour), post-surgery 4 hours, 8 hours, and 24 hours by an anesthesiology resident who was blinded to the present study. Also, a sleep disturbance 24 hours after surgery was recorded. If the patient complained of pain in the recovery room, the pain score was recorded and fentanyl $50 \mu \mathrm{g}$ was administered. Ten minutes following, pain was reassessed. If it was not controlled or the patient was not satisfied, fentanyl 50 $\mu \mathrm{g}$ readministered until there were no side-effects of fentanyl. Afterwards, on the patient ward, tramadol hydrochloride 50 mg iv was administered twice in an 8-hr interval. If the patient requested additional analgesics, tramadol hydrochloride $50 \mathrm{mg}$ was administered.

In the pilot study NRS in the recovery room for the control

Table 1. Characteristics of the Patients

\begin{tabular}{lcc}
\hline & $\begin{array}{c}\text { Control group } \\
(\mathrm{n}=20)\end{array}$ & $\begin{array}{c}\text { TAPB group } \\
(\mathrm{n}=20)\end{array}$ \\
\hline Age (yr) & $58.2 \pm 18.8$ & $49.9 \pm 18.9$ \\
Gender (M/F) & $18 / 2$ & $19 / 1$ \\
Weight (kg) & $63.2 \pm 8.6$ & $65.5 \pm 8.9$ \\
Heigh t (cm) & $165.8 \pm 8.1$ & $170.2 \pm 7.7$ \\
Duration of surgery (min) & $41.0 \pm 12.7$ & $37.5 \pm 12.3$ \\
Duration of anesthesia (min) & $73.0 \pm 14.9$ & $75.8 \pm 15.8$ \\
Type of surgery (Rt/Lt/Both) & $13 / 4 / 3$ & $10 / 6 / 4$ \\
\hline
\end{tabular}

Data are expressed as mean \pm SD or number of patients. No statistical significant differences were calculated between the groups. group was 7 with a standard deviation of 1.7 , so a NRS below 5 for the TAPB group was considered clinically significant. By calculating $\alpha=0.05$ and power $=0.9$, each group was supposed to have 17 patients as for sample size. Statistical analysis was done using SPSS (version 14.0, SPSS Inc., Chicago, IL, USA). The Student t-test was used for continuous variables and the chi-square test and Fisher's exact test were used for categorical variables. Pain scores were shown as mean \pm standard deviation. P value below 0.05 was considered statistically significant.

\section{Results}

There were no differences between the two groups in age, gender, height, weight, operative time, anesthesia time, or surgical site (Table 1). Post-operative pain in the TAPB group compared to the control group was significantly low at $20 \mathrm{~min}$ after surgery and at discharge from the recovery room. 4 hours and 8 hours following surgery only pain on coughing was significantly low in the TAPB group (Table 2). After 24 hours there was no difference between levels of pain at rest and when coughing. The mean dosage of remifentanil administered

Table 2. Postoperative Pain Score (Numeric Rating Scale, NRS)

\begin{tabular}{lccc}
\hline & $\begin{array}{c}\text { Control group } \\
(\mathrm{n}=20)\end{array}$ & $\begin{array}{c}\text { TAPB group } \\
(\mathrm{n}=20)\end{array}$ & P values \\
\hline Postop $20 \mathrm{~min}$ & & & \\
$\quad$ Rest & $6.9 \pm 1.6$ & $3.9 \pm 1.6$ & $\mathbf{0 . 0 0 1}$ \\
$\quad$ Cough & $8.0 \pm 1.6$ & $4.9 \pm 1.8$ & $\mathbf{0 . 0 0 1}$ \\
Discharge of recovery room & & & \\
(Postop 1 hr) & & & \\
$\quad$ Rest & $5.3 \pm 1.6$ & $3.2 \pm 1.2$ & $\mathbf{0 . 0 0 1}$ \\
$\quad$ Cough & $6.5 \pm 1.8$ & $4.2 \pm 1.5$ & $\mathbf{0 . 0 0 1}$ \\
Postop 4 hr & & & \\
$\quad$ Rest & $3.6 \pm 1.4$ & $3.1 \pm 1.4$ & 0.31 \\
$\quad$ Cough & $6.1 \pm 1.9$ & $4.7 \pm 1.5$ & $\mathbf{0 . 0 1}$ \\
Postop $8 \mathrm{hr}$ & & & \\
$\quad$ Rest & $2.2 \pm 1.0$ & $2.2 \pm 1.3$ & 0.89 \\
$\quad$ Cough & $5.1 \pm 1.8$ & $3.9 \pm 1.6$ & $\mathbf{0 . 0 2}$ \\
Postop 24 hr & & & \\
$\quad$ Rest & $1.0 \pm 1.1$ & $1.3 \pm 1.0$ & 0.29 \\
Cough & $2.9 \pm 1.7$ & $3.3 \pm 1.5$ & 0.44 \\
\hline
\end{tabular}

Data are presented as mean \pm SD. NRS $(0=$ no pain, $10=$ maximal pain).

Table 3. Opioid Requirement, Sleep Disturbance

\begin{tabular}{|c|c|c|c|}
\hline & Control group $(n=20)$ & TAPB group $(n=20)$ & $P$ values \\
\hline Remifentanil requirement $(\mu \mathrm{g} / \mathrm{kg} / \mathrm{min})$ & $0.07 \pm 0.03$ & $0.05 \pm 0.02$ & 0.004 \\
\hline$(\mu \mathrm{g})$ & $313.0 \pm 116.8$ & $217.0 \pm 99.5$ & 0.008 \\
\hline Fentanyl requirement $(\mu \mathrm{g})$ & $80.0 \pm 49.7$ & $30.0 \pm 49.7$ & 0.003 \\
\hline Sleep disturbance & 3 & 0 & 0.23 \\
\hline
\end{tabular}

Data are presented as mean \pm SD and number of patients. 
during surgery and the mean dosage of fentanyl administered in the recovery room was significantly lower in the TAPB group (Table 3). Also, the number of patients who wanted analgesics in the recovery room was significantly lower in the TAPB (8 patients from the TAPB group and 17 patients from the control group; $\mathrm{P}=0.008$ ). Only 2 patients from the control group wanted extra analgesics on the ward, so they each were administered tramadol hydrochloride $50 \mathrm{mg}$ iv once. There was no statistical significance between the two groups in sleep disturbance.

\section{Discussion}

Laparoscopic surgeries are known to involve less pain compared to open surgeries. But there are many patients who complain of severe postoperative pain, and there are cases where this can develop into chronic pain. So there are studies underway focused on methods to control pain. Invasive stimulation due to surgery can cause central sensitization which can lead to chronic pain. Preemptive analgesia [9] has been introduced to block this, and studies have been performed using it even in laparoscopic surgeries. Also pain characteristics have been categorized in an attempt to effectively control different types of pain.

Because of viscera-somatic convergence, it is difficult to clinically differentiate somatic and visceral pain [10]. However, Kim et al. [11] have classified somatic pain as clearly localized pain limited to the peritoneal wall of the surgical site, and visceral pain as dull, nonlocalized, general, squeezing pain. They studied pain patterns in patients lying still in the supine position, and they found that after cholecystectomy by laparoscopy, somatic pain was greater than visceral pain. Also, when $0.25 \%$ bupivacaine $20 \mathrm{ml}$ was locally infiltrated into the peritoneal wall before surgery, it delayed the first use of analgesics, its dosage, and the severity of pain [4].

On the other hand, Joris et al. [12] stated that visceral pain was greater than somatic pain in patients with cholecystectomy by laparoscopy. Also Pasqualucci et al. [5] stated that in cholecystectomy by laparoscopy, the administration of $0.5 \%$ bupivacaine $20 \mathrm{ml}$ in the peritoneal space for visceral pain prevention against stimulation of the diaphragm by carbon dioxide and surgical manipulation was effective in pain alleviation for the first day after surgery.

In the present study our analysis did not differentiate between somatic and visceral pain. But there was not even one patient who complained of shoulder pain, which is a sign of diaphragmatic stimulation from the infusion of carbon dioxide. There was one patient who complained of scrotal pain. The areas of pain that patients severely complained of were sharp pain at the navel area where the trocar had been inserted and dull pain at the hernia site where surgical manipulation had been performed. Thus the pain patterns were diverse.

Also in inguinal hernia repair, laparoscopy is known to have lower pain than open surgery [2]. But in the pilot study there were many patients who needed opioid analgesics because of severe pain in the recovery room. Lau et al. [13] reported that $9.2 \%$ of 313 patients who had TEP experienced postoperative chronic pain, and they reported that severe postoperative pain is a risk factor for chronic pain. They stated that to deal with such acute and chronic pain, the ilioinguinaliliohypogastric nerve block in open inguinal herniorrhaphy is blindly performed, which reduces post-operative pain and aids in early ambulation [14]. However, complications such as intestinal perforation and subserous hematoma are reported in pediatric patients $[15,16]$. So recently ultrasound-guided studies have been performed to increase accuracy [17]. Aveline et al. [18] reported that ultrasound-guided TAPB controls pain on the day of surgery much better than the blind ilioinguinaliliohypogastric nerve block in open inguinal herniorrhaphy.

Because the TEP was performed in the extraperitoneal area, we assumed that the pain patients complained about was somatic pain. We applied the preemptive analgesia for abdominal surgeries suggested by the previous studies, and we expected that preoperative ultrasound-guided TAPB would continuously and completely control post-TEP pain. But the results fell short of our expectations.

In 2001, Rafi first described the traditional TAPB method, where a blunt needle was blindly inserted vertically in the 'triangle of petit' (marked by the iliac crest, external abdominal oblique muscle, and latissimus dorsi muscle), and after feeling a 'pop' when the fascia was punctured, local anesthetics were infused. McDonnell et al. [19-21] stated that when TAPB was performed with this method, they saw sensory loss from T7 to L1, and they reported that bilateral TAPB performed in caesarean sections and large bowel resections reduced postoperative pain and decreased the dosage of morphine used by patient-controlled analgesia by more than $70 \%$. Carney et al. [22] performed unilateral TAPB with the same method in an open appendectomy and were able to reduce morphine dosage by more than $50 \%$. However, the blind method is reported to have complications such as the needle directly damaging the liver [23], and the procedure faces drawbacks with obese patients because it is difficult to assess the depth of the needle with them.

Recently, the use of ultrasound-guides has increased. Hebbard et al. [8] introduced the mid-axillary approach where the direct location of the needle can be seen and local anesthetics is accurately injected into the TAP. With the same method, TAPBs were used for various abdominal surgeries such as laparoscopic cholecystectomies, caesarean sections, and open appendectomies; reducing the dosage of opioid analgesics 
and having effective results for pain control [6,24,25]. However, Tran et al. [26] performed a cadaver study using the Hebbard method and saw that only T10-L1 was stained when they used a dye $20 \mathrm{ml}$. So they stated that rather than the traditional method using the 'triangle of petit,' the ultrasound-guided mid-axillary approach could be used restrictively for lower abdominal surgery. Therefore in the present study for the lower abdominal surgery, an ultrasound-guided TAPB was performed, and the mid-axillary approach was used, which did not require a change in the patient's position after anesthesia induction. As a result we were able to reduce post-operative pain in the recovery room and the dosage of analgesics. However, we could not continuously reduce pain until post-surgery 24 hours as was accomplished in the study by Ra et al. [7].

In the study by Carney et al. [27], when TAPB was performed they used contrast media to observe the changes in an MRI over time. With the mid-axillary approach, the contrast media spread in most TAPs, and 4 hours after injection there was hardly any contrast media left. However, in the lateral position with the posterior approach between the quadratus lumborum and lateral abdominal muscles, the contrast media pooled around the quadratus lumborum and spread to the paravertebral region, and even after 4 hours the contrast media had decreased but still remained. Also among the ultrasoundguided approaches, the posterior approach had the most similar pattern to traditional TAPB in contrast media deposits.

The present study results demonstrated that we did not have a continuous and complete pain control compared to the control group. The reason is considered to be due to the fact that the mid-axillary approach, as in the afore-mentioned studies, compared to traditional approaches had a short action time and only a very small amount diffused to the paraspinal region, so its analgesic effect is considered to have been small. Another reason could be that pain reduction on the day of surgery is faster than other laparoscopic procedures [7].

In the present study, a total of ropivacaine $112.5 \mathrm{mg}$ was used. When Griffiths et al. [28] performed ultrasound-guided bilateral TAPB in women who had obstetric surgeries, they administered $3 \mathrm{mg} / \mathrm{kg}$ ropivacaine diluted to $40 \mathrm{ml}$. They stated that the 30 min peak blood concentration reached a mean $2.54 \pm 0.37 \mu \mathrm{g} / \mathrm{ml}$. The highest concentration level in a patient was $4.00 \mu \mathrm{g} / \mathrm{ml}$. Also the highest blood concentration up to 90 min was at least a mean $2.2 \mu \mathrm{g} / \mathrm{ml}$. In a similar study, Latzke et al. [29] reported that after ropivacaine $150 \mathrm{mg}$ was administered to healthy men, the highest blood concentration was a mean $1.88 \pm 0.37 \mu \mathrm{g} / \mathrm{ml}$. Combining the findings of the two studies, it seems that after TAPB, the blood concentration of ropivacaine is not affected by age, gender, or body fat, and the blood concentration ropivacaine that causes neurological symptoms in healthy men is about $2.2 \mu \mathrm{g} / \mathrm{ml}$ [30]. When TAPB is performed, one must always be mindful of the possibility of side effects of ropivacaine. In short surgeries the patient's condition must be carefully observed even after surgery.

Ra et al. [7] stated that ultrasound-guided TEP in cholecystectomy by laparoscopy reduced post-operative pain and dosage of analgesics compared to the control group, but there was no significant difference between the groups that used $0.25 \%$ and $0.5 \%$ bupivacaine $30 \mathrm{ml}$. We therefore used $0.375 \%$ ropivacaine $30 \mathrm{ml}$ in the present study. The operative time was short, but there were no patients showing neurologic symptoms.

Low visceral pain and high somatic pain are expected with TEP. The significance of the study is that it is the first to look into the effects of the pre-operative ultrasound-guided TAPB by the mid-axillary approach on pain control in TEP.

The limitation of this study is that we performed TAPB after general anesthesia so we could not evaluate the range of the nerve block. The study by Latzke et al. [29] stated that if the administered local anesthetics do not accurately diffuse, that the concentration of the local anesthetics at the target site can be lower than the blood concentration, and the nerve block may have no effect. However, the ultrasound-guided TAPB was performed by an anesthesiologist that had experience performing more than 200 ultrasound guided nerve blocks, and we tried to administer local anesthetics to deeper fascia in TAP.

In conclusion, ultrasound-guided bilateral TAPB significantly reduced post-TEP pain in the recovery room and reduced analgesic dosage. Also it significantly reduced pain on coughing until 8 hours after surgery.

\section{References}

1. Memon MA, Cooper NJ, Memon B, Memon MI, Abrams KR. Metaanalysis of randomized clinical trials comparing open and laparoscopic inguinal hernia repair. Br J Surg 2003; 90: 1479-92.

2. Bittner R, Arregui ME, Bisgaard T, Dudai M, Ferzli GS, Fitzgibbons RJ, et al. Guidelines for laparoscopic (TAPP) and endoscopic (TEP) treatment of inguinal hernia [International Endohernia Society (IEHS)]. Surg Endosc 2011; 25: 2773-843.

3. Kim DE, Kang WJ, Choi JH, Yi JW, Park SW. The effects of perioperative intravenous lidocaine injection on postoperative pain following laparoscopic cholecystectomy. Korean J Anesthesiol 2008; 54: 69-73.

4. Kim SB, Lee IO, Kong MH, Lee MK, Kim NS, Choi YS, et al. Preemptive analgesia of local infiltration with bupivacaine for laparoscopic cholecystectomy. Korean J Anesthesiol 1999; 37: 1101-8.

5. Pasqualucci A, de Angelis V, Contardo R, Colo F, Terrosu G, Donini A, et al. Preemptive analgesia: intraperitoneal local anesthetic in laparoscopic cholecystectomy. A randomized, double-blind, placebo-controlled study. Anesthesiology 1996; 85: 11-20.

6. El-Dawlatly AA, Turkistani A, Kettner SC, Machata AM, Delvi $\mathrm{MB}$, Thallaj A, et al. Ultrasound-guided transversus abdominis 
plane block: description of a new technique and comparison with conventional systemic analgesia during laparoscopic cholecystectomy. Br J Anaesth 2009; 102: 763-7.

7. Ra YS, Kim CH, Lee GY, Han JI. The analgesic effect of the ultrasound-guided transverse abdominis plane block after laparoscopic cholecystectomy. Korean J Anesthesiol 2010; 58: 362-8.

8. Hebbard P, Fujiwara Y, Shibata Y, Royse C. Ultrasound-guided transversus abdominis plane (TAP) block. Anaesth Intensive Care 2007; 35: 616-7.

9. Woolf CJ, Chong MS. Preemptive analgesia--treating postoperative pain by preventing the establishment of central sensitization. Anesth Analg 1993; 77: 362-79.

10. Griffin R, Fink E, Brenner GJ. Functional neuroanatomy of the nociceptive system. In: Bonica's management of pain. 4th ed. Edited by Fishman SM, Ballantyne JC, Rathmell JP: Baltimore, Lippincott Williams \& Wilkins. 2010, p 99.

11. Kim SB, Lee IO, Kong MH, Lee MK, Kim NS, Choi YS, et al. Pain after a laparoscopic cholecystectomy: comparison between somatic pain and visceral pain. Korean J Anesthesiol 2001; 41: 66-70.

12. Joris J, Thiry E, Paris P, Weerts J, Lamy M. Pain after laparoscopic cholecystectomy: characteristics and effect of intraperitoneal bupivacaine. Anesth Analg 1995; 81: 379-84.

13. Lau H, Patil NG, Yuen WK, Lee F. Prevalence and severity of chronic groin pain after endoscopic totally extraperitoneal inguinal hernioplasty. Surg Endosc 2003; 17: 1620-3.

14. Langer JC, Shandling B, Rosenberg M. Intraoperative bupivacaine during outpatient hernia repair in children: a randomized double blind trial. J Pediatr Surg 1987; 22: 267-70.

15. Frigon C, Mai R, Valois-Gomez T, Desparmet J. Bowel hematoma following an iliohypogastric-ilioinguinal nerve block. Paediatr Anaesth 2006; 16: 993-6.

16. Jöhr M, Sossai R. Colonic puncture during ilioinguinal nerve block in a child. Anesth Analg 1999; 88: 1051-2.

17. Willschke H, Marhofer P, Bosenberg A, Johnston S, Wanzel O, Cox $\mathrm{SG}$, et al. Ultrasonography for ilioinguinal/iliohypogastric nerve blocks in children. Br J Anaesth 2005; 95: 226-30.

18. Aveline C, Le Hetet H, Le Roux A, Vautier P, Cognet F, Vinet E, et al. Comparison between ultrasound-guided transversus abdominis plane and conventional ilioinguinal/iliohypogastric nerve blocks for day-case open inguinal hernia repair. Br J Anaesth 2011; 106: 380-6.

19. McDonnell JG, Curley G, Carney J, Benton A, Costello J, Maharaj
$\mathrm{CH}$, et al. The analgesic efficacy of transversus abdominis plane block after cesarean delivery: a randomized controlled trial. Anesth Analg 2008; 106: 186-91.

20. McDonnell JG, O'Donnell B, Curley G, Heffernan A, Power C, Laffey JG. The analgesic efficacy of transversus abdominis plane block after abdominal surgery: a prospective randomized controlled trial. Anesth Analg 2007; 104: 193-7.

21. McDonnell JG, O'Donnell BD, Farrell T, Gough N, Tuite D, Power C, et al. Transversus abdominis plane block: a cadaveric and radiological evaluation. Reg Anesth Pain Med 2007; 32: 399-404.

22. Carney J, Finnerty O, Rauf J, Curley G, McDonnell JG, Laffey JG. Ipsilateral transversus abdominis plane block provides effective analgesia after appendectomy in children: a randomized controlled trial. Anesth Analg 2010; 111: 998-1003.

23. Farooq M, Carey M. A case of liver trauma with a blunt regional anesthesia needle while performing transversus abdominis plane block. Reg Anesth Pain Med 2008; 33: 274-5.

24. Niraj G, Searle A, Mathews M, Misra V, Baban M, Kiani S, et al. Analgesic efficacy of ultrasound-guided transversus abdominis plane block in patients undergoing open appendicectomy. Br J Anaesth 2009; 103: 601-5.

25. Belavy D, Cowlishaw PJ, Howes M, Phillips F. Ultrasound-guided transversus abdominis plane block for analgesia after Caesarean delivery. Br J Anaesth 2009; 103: 726-30.

26. Tran TM, Ivanusic JJ, Hebbard P, Barrington MJ. Determination of spread of injectate after ultrasound-guided transversus abdominis plane block: a cadaveric study. Br J Anaesth 2009; 102: 123-7.

27. Carney J, Finnerty O, Rauf J, Bergin D, Laffey JG, Mc Donnell JG. Studies on the spread of local anaesthetic solution in transversus abdominis plane blocks. Anaesthesia 2011; 66: 1023-30.

28. Griffiths JD, Barron FA, Grant S, Bjorksten AR, Hebbard P, Royse CF. Plasma ropivacaine concentrations after ultrasound-guided transversus abdominis plane block. Br J Anaesth 2010; 105: 853-6.

29. Latzke D, Marhofer P, Kettner SC, Koppatz K, Turnheim K, Lackner E, et al. Pharmacokinetics of the local anesthetic ropivacaine after transversus abdominis plane block in healthy volunteers. Eur J Clin Pharmacol 2012; 68: 419-25.

30. Knudsen K, Beckman Suurkula M, Blomberg S, Sjovall J, Edvardsson N. Central nervous and cardiovascular effects of i.v. infusions of ropivacaine, bupivacaine and placebo in volunteers. Br J Anaesth 1997; 78: 507-14. 


\title{
Effect of timing of morphine administration during propofol - remifentanil anesthesia on the requirements of post-operative analgesia
}

\author{
Farid Zand ${ }^{1}$, Afshin Amini ${ }^{1,2}$, and Seyed Alireza Hamidi ${ }^{3}$ \\ Department of Anesthesia, ${ }^{1}$ Anesthesiology and Critical Care Research Center, Shiraz University of Medical Science, ${ }^{2}$ Nemazee \\ Hospital, Nemazee Square, ${ }^{3}$ Rajaee Trauma Center, Shiraz University of Medical Sciences, Shiraz, Iran
}

Background: An important concern of intra-operative infusion of remifentanil is the possible development of acute opioid tolerance, which manifests as an increased postoperative analgesia requirement. We have examined the effect of the timing of intra operative morphine administration on the need for morphine consumption for pain control during the first 24 hours after operation.

Methods: Sixty adult patients scheduled for elective open unilateral nephrolithotomy surgery were recruited for this prospective randomized double-blind study. Anesthesia was induced with $0.03 \mathrm{mg} / \mathrm{kg}$ midazolam, $1 \mu \mathrm{g} / \mathrm{kg}$ remifentanil, and $1.5-2 \mathrm{mg} / \mathrm{kg}$ propofol. Anesthesia was maintained with $100 \mu \mathrm{g} / \mathrm{kg} / \mathrm{min}$ propofol, and $0.25 \mu \mathrm{g} /$ $\mathrm{kg} / \mathrm{min}$ remifentanil. Both groups received $0.1 \mathrm{mg} / \mathrm{kg}$ morphine intravenously at 2 different times; in the first group (group E) immediately after intubation and in the second group (group L) 20-30 min before the anticipated end of operation.

Results: There was no difference in pain scores at awakening, the amount of morphine given to the 2 groups for pain control, or the time to discharge from PACU between the 2 groups. The pain scores at admission to ward and at every 4 hours thereafter, until 24 hours, were not significantly different between the 2 groups. The cumulative amount of the first 24 hours morphine consumption in the ward in E group was $28.2 \pm 20.1 \mathrm{mg}$ and $26.5 \pm 15 \mathrm{mg}$ in L group, respectively $(\mathrm{P}=0.71)$.

Conclusions: Early intra-operative administration of morphine compared to that of morphine in the end of surgery did not affect postoperative morphine consumption and pain scores during the first 24 hours after surgery for open nephrolithotomy. Newer pharmacologic interventions for prevention of acute tolerance of opioids seems rational (Clinical trial registration No. ACTRN: 12609000570280). (Korean J Anesthesiol 2012; 63: 233-237)

Key Words: Morphine, Postoperative pain, Propofol, Remifentanil.

Received: October 31, 2011. Revised: 1st, December 16, 2011; 2nd, January 22, 2012; 3rd, June 15, 2012; 4th, July 1, 2012; 5th, July 4, $2012 ;$ 6th, July 10, 2012. Accepted: July 17, 2011.

Corresponding author: Afshin Amini, M.D., Department of Anesthesia, Nemazee Hospital, Nemazee Square, Shiraz 71345 11351, Iran. Tel: 98 711-647-4270, Fax: 98-711-647-4270, E-mail: aamini@sums.ac.ir

@ This is an open-access article distributed under the terms of the Creative Commons Attribution Non-Commercial License (http:// creativecommons.org/licenses/by-nc/3.0/), which permits unrestricted non-commercial use, distribution, and reproduction in any medium, provided the original work is properly cited. 


\section{Introduction}

Potent opioids with short duration of action are widely used as analgesic agents in anesthesia. Intra-operative infusion of remifentanil hydrochloride with propofol is an established technique that is commonly used to meet anesthesia needs. The ultra-short duration of action of remifentanil is independent of dose, allowing infusion of large doses throughout surgery with little risk of postoperative delayed awakening or respiratory depression [1,2]. However, this characteristic may be a disadvantage at the end of anesthesia as the rapid cessation of the effect of remifentanil can result in early and severe postoperative pain if the analgesic regimen has not been started prior to the end of surgery $[3,4]$.

Another important concern with intraoperative infusion of remifentanil is the possible development of acute opioid tolerance and/or hyperalgesia, manifesting as an increased requirement for postoperative analgesic [5-8]. There is evidence that a high-dose infusion of a short- acting opioid during painful surgery may induce tolerance more rapidly than would be expected with a long-acting drug [9-14]. Profound tolerance has been demonstrated after only 60-90 min of remifentanil infusion in volunteers, [14] but the clinical consequences of acute tolerance to remifentanil have not been evaluated to date.

Various methods have been evaluated to attenuate the development of remifentanil induced hyperalgesia; the majority of these methods have focused on the N-methyl-D-aspartate antagonist, ketamine, with little if any benefit [15-17] Rotational regimens or combination of opioids have been proposed to decrease or prevent opioid-induced hyperalgesia [18]. In this study, we measured the total amount of morphine consumed by patients for postoperative pain control and pain scores during the first 24 hours after surgery.

\section{Materials and Methods}

After approval by the Ethics Committee of Shiraz University of Medical Sciences a written informed consent was obtained from each participating patient, all of which were 60 adults aged 40-70 years old, with American Society of Anesthesiologists physical status I or II scheduled to undergo elective open unilateral nephrolithatomy were recruited for this prospective randomized double-blind study. Patients were excluded preoperatively if they had a history of acute or chronic kidney injury, drug abuse, received any analgesic medications during the previous 48 hours or were unable to use a patient-controlled analgesia device. The patients were instructed to explain their pain according to a numerical rating scale (NRS) from zero (no pain) to 10 (worst imaginable pain). Randomization of the subjects using a computer generated random numbers was performed on the day of surgery.

All patients received premedication with 5-10 mg diazepam the night before their operation. Electrocardiography, pulse oximetry, capnography, and non-invasive blood pressure monitoring was used in all patients. After preoxygenation, anesthesia was induced with $0.03 \mathrm{mg} / \mathrm{kg}$ midazolam, $1 \mu \mathrm{g} / \mathrm{kg}$ remifentanil, and $1.5-2 \mathrm{mg} / \mathrm{kg}$ propofol. Muscle relaxation was provided by $0.5 \mathrm{mg} / \mathrm{kg}$ atracurium and endotracheal intubation was done after 3 min of bag and mask ventilation. Mechanical ventilation was started to maintain normocarbia. Anesthesia was maintained with $100 \mu \mathrm{g} / \mathrm{kg} / \mathrm{min}$ propofol, $0.25 \mu \mathrm{g} / \mathrm{kg} / \mathrm{min}$ remifentanil, and a mixture of $\mathrm{O}_{2}$ and $\mathrm{N}_{2} \mathrm{O}$ in $50: 50$ ratios. Both groups received $0.1 \mathrm{mg} / \mathrm{kg}$ morphine intravenously diluted in normal saline to a concentration of $1 \mathrm{mg} / \mathrm{ml}$ at 2 different times; in the first group (group E) immediately after intubation and in the second group (group L) 20-30 min before the anticipated end of operation. The remifentanil infusion was adapted by the anesthetist in steps of $0.05 \mu \mathrm{g} / \mathrm{kg} / \mathrm{min}$ according to variations of heart rate and arterial systolic pressure. Heart rate and systolic blood pressure were kept within $20 \%$ of pre-induction values. The patient's bladder was catheterized according to routine practice.

Intravenous fluids were infused according to the anesthetist's discretion. After skin closure; end of surgery, propofol, and remifentanil administration were discontinued and residual neuromuscular blockade was antagonized with intravenous neostigmine and atropine. The trachea was extubated when patients where responsive to verbal commands, end-tidal carbon dioxide partial pressure was acceptable, and tidal volume was more than $5 \mathrm{mg} / \mathrm{kg}$. Patients were transferred to the post anesthesia care unit (PACU) within 5 min after tracheal extubation. After awakening in PACU (T1), the pain score was recorded according to numerical rating scale by a nurse, who was blinded to the patient study assignments. If the NRS was more than 3, morphine was given intravenously, in increments of $1 \mathrm{mg}$, every $10 \mathrm{~min}$ until the pain score decreased to 3 or less. The total dose of morphine needed was recorded. Next, a patient-control analgesia pump (Microject, Sorenson Medical and West Jordan, UT, USA) was started. The morphine solution was prepared in $20 \mathrm{ml}$ boluses with a concentration of $1 \mathrm{mg} /$ $\mathrm{ml}$. The interval lockout time was $10 \mathrm{~min}$ and bolus dose was set to $2 \mathrm{mg}$ without a background infusion. The maximum permissible dose was $20 \mathrm{mg}$.

Discharge from the PACU was with recommendation of the nurse and at the discretion of the anesthetist (T2). Each patient's pain score at the arrival to ward (T3) and at every 4 hours thereafter, up to 24 hours were recorded by nurses blinded to treatment . No other analgesics were administrated during the 24 hours observation period. The recorded NRS in each time scale, the total number of successful and unsuccessful attempts 
of patients to activate the PCA pump, and total morphine consumption were recorded and compared between 2 groups with appropriated statistical tests.

The sample size was chosen on the basis of similar studies with a power of $90 \%$ with an $\alpha$ level of 0.05 and a minimal difference to be detected in a post-operative morphine consumption of $30 \%$. Patient characteristics and clinical variables were compared using $\mathrm{X}^{2}$-test or t-test. Repeated measures analysis of variance was used for comparison of morphine consumption. The Mann-Whitney rank sum test was used for comparison of NRS pain scores. Data analysis was performed using SPSS software version 13 (Chicago, Il, USA).

\section{Results}

All 60 patients completed the study. Both groups were similar with respect to age, weight, gender, duration of anesthesia, and surgery and hemodynamic variables during the operation (Table 1). In addition, there was also no difference in pain scores at awakening, morphine given to the two groups for pain control and time to discharge from PACU between the 2 groups (Table 2). There was no difference in pain scores (NRS) at admission to ward and at every 4 hours thereafter until 24 hours between the 2 groups. Median and $25-75 \%$ interquartile numeric rating scale pain scores of the patients in the recovery room, on arrival to ward, and at every 4 hours thereafter are shown in Fig. 1.

Table 1. Demographic Characteristics and Operation Data of Group E (Early Morphine) vs. Group L (Late Morphine)

\begin{tabular}{lccc}
\hline & Group E & Group L & P value \\
\hline Age (yr) & $48.3 \pm 12.4$ & $49.8 \pm 13.8$ & 0.66 \\
Weight (kg) & $64.4 \pm 11.0$ & $69.3 \pm 12.3$ & 0.10 \\
Duration of anesthesia (min) & $124.7 \pm 40$ & $128.1 \pm 28$ & 0.70 \\
Duration of operation (min) & $118.9 \pm 39$ & $121.1 \pm 29$ & 0.80 \\
Sex (M/F) & $14 / 16$ & $17 / 13$ & 0.43 \\
Time to awakening (min) & $28.2 \pm 20.1$ & $31.3 \pm 20.4$ & 0.56 \\
\hline
\end{tabular}

Data are presented as mean \pm standard deviation. Group E: early administration of morphine, Group L: morphine administration at the end of surgery.
The cumulative dose of morphine used by the patients during the first post-op day was similar, as well. The cumulative first 24 hours morphine consumption in the ward in E group was $28.2 \pm 20.1 \mathrm{mg}$ and $26.5 \pm 15 \mathrm{mg}$ in $\mathrm{L}$ group $(\mathrm{P}=0.71)$. No patient experienced a serious adverse effect. The total number of the patient attempts to activate the PCA pump and total number of successful drug delivery to the patients were similar in both groups $(\mathrm{P}=0.96)$ (Table 2$)$.

\section{Discussion}

In this study, the time of morphine administration during the operation did not have any significant effect on the amount of morphine, post-operative, for pain control during the first 24 hours. This is not in agreement with the untested clinical practice that uses a bolus of morphine prior to initiating remifentanil by infusion. However, this finding, is in agreement with 2 recent investigations in which fentanyl or morphine pretreatment in orthopedic surgery was used to reduce acute

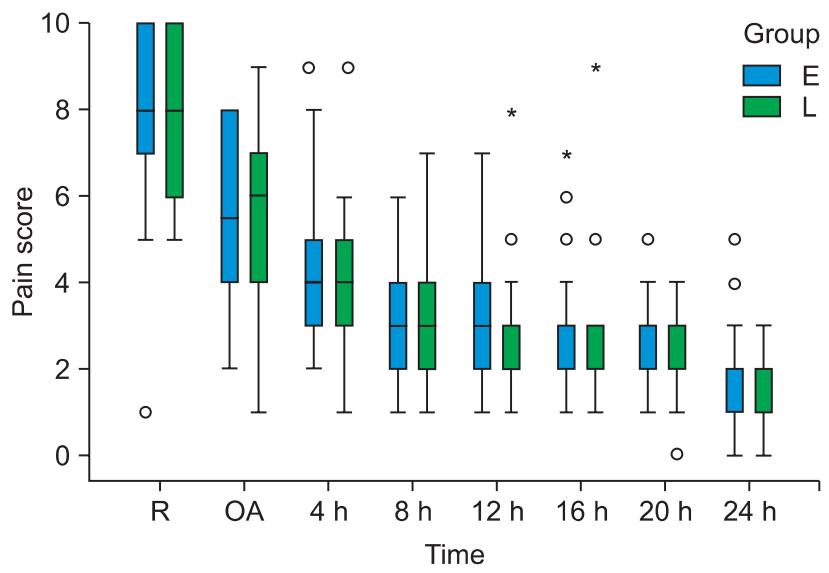

Fig. 1. Box and whisker plots showing median and $25-75 \%$ interquartile, numeric rating scale pain scores of the patients in the recovery room $(\mathrm{R})$, on arrival to ward $(\mathrm{OA})$ and every 4 hours thereafter (Group E: Early morphine , Group L: Late morphine). Circles represent points that are $>1.5$ times the interquartile range. Asterisks represent points that are $>3$ times the interquartile range. ${ }^{*}$ Than three times the interquartile range.

Table 2. Comparison of Pain Scores and Morphine Requirements between Group E (Early Morphine) vs. Group L (Late Morphine)

\begin{tabular}{lcc}
\hline & Group E & Group L value \\
\hline Pain on awakening (NRS) & $8(7-10)$ & $8(6-10)$ \\
Morphine consumption in PACU (mg) & $4.9 \pm 2.1$ & $4.8 \pm 1.4$ \\
Patient stay in PACU (Min) & $95.5 \pm 41.6$ & $98.2 \pm 38.1$ \\
Total patients attempt on PCA pump & $28 \pm 26.9$ & $25.6 \pm 22.2$ \\
Successful patient attempts on PCA pump & $14.1 \pm 10$ & $13.2 \pm 7.6$ \\
Cumulative used morphine in ward (mg) & $28.2 \pm 20.1$ & 0.79 \\
\hline
\end{tabular}

Data are presented as mean \pm SD or median (interquartile range). NRS: numerical rating scale, PACU: post-anesthesia care unit, PCA: patientcontrolled analgesia. 
tolerance to remifentanil $[19,20]$.

Acute tolerance is reported by administration of many opioids including morphine, sufentanil, and alfentanil [9,10,12,13,21,22]; the intensity of tolerance has been reported by some investigators to be unrelated to the potency of the opioid used [13]. Although opioids with shorter duration of action show a faster development of tolerance, it is likely that the use of a different opioid, other than morphine, is not a good choice for preventing acute tolerance.

We could not comment on the development of remifentanilinduced hyperalgesia because we considered it unethical to include a group with no morphine consumption perioperatively. However, based on previous studies [5-8], it is not unusual to see this phenomenon when low doses of remifentanil are used to treat pain for surgical operations. Even if our patients were susceptible, based on current study, we couldn't find any relation between the timing of morphine administration and remifentanil-induced hyperalgesia.

Some investigators recommend that development of remifentanil-induced hyperalgesia is related to duration and dose of used remifentanil rather than time of morphine administration $[5,19,23]$. This is in agreement with our findings as the duration of anesthesia and surgery was very similar in both groups in our study. We titrated the dose of remifentanil according to hemodynamic variables in our study, and we didn't saw any significant difference on analgesic needs between the 2 groups; remifentanil consumption was similar during the operation. However, this study was not powered to detect this difference in the analgesic requirements.

Muñoz et al. [3] looked at the effect of timing of morphine administration on early post-operative pain score and recovery condition of patients after laparoscopic cholecystectomy with remifentanil based anesthesia. These researchers concurred with our results, in that they did not find any significant difference in patient pain scores in the recovery period; however, they reported lower pain scores when $150 \mu \mathrm{g} / \mathrm{kg}$ morphine had been given more than $40 \mathrm{~min}$ before the end of surgery. This result was attributed by the investigators to a better matching between the time of morphine administration and its peak analgesia effect at the moment of arrival at the PACU rather than pre-emptive effects of morphine [3].

In conclusion, our study shows that earlier use of morphine during remifentanil-based anesthesia causes no less morphine consumption during the first 24 hours after surgery for open nephrolithatomy. We suggest future studies on analgesic requirements after remifentanil-based anesthesia that focus on the effect of the total dose and duration of remifentanil infusion on the development of acute tolerance. New pharmacologic interventions for prevention of this undesirable side effect seem rational as well.

\section{Acknowledgments}

The authors would like to thank Leila Ghazanfari for typing the manuscript and Clinical Research Development Center in Nemazee Hospital of statistical analysis.

\section{References}

1. Crawford MW, Hickey C, Zaarour C, Howard A, Naser B. Development of acute opioid tolerance during infusion of remifentanil for pediatric scoliosis surgery. Anesth Analg 2006; 102: 1662-7.

2. Thompson JP, Rowbotham DJ. Remifentanil--an opioid for the 21st century. Br J Anaesth 1996; 76: 341-3.

3. Muñoz HR, Guerrero ME, Brandes V, Cortínez LI. Effect of timing of morphine administration during remifentanil-based anaesthesia on early recovery from anaesthesia and postoperative pain. $\mathrm{Br} \mathrm{J}$ Anaesth 2002; 88: 814-8.

4. Albrecht S, Schuttler J, Yarmush J. Postoperative pain management after intraoperative remifentanil. Anesth Analg 1999; 89(4 Suppl): S40-5.

5. Guignard B, Bossard AE, Coste C, Sessler DI, Lebrault C, Alfonsi P, et al. Acute opioid tolerance: Intraoperative remifentanil increases postoperative pain and morphine requirement. Anesthesiology 2000; 93: 409-17.

6. Jo HR, Chae YK, Kim YH, Chai HS, Lee WK, Choi SS, et al. Remifentanil-Induced pronociceptive effect and its prevention with pregabalin. Korean J Anesthesiol 2011; 60: 198-204.

7. Joly V, Richebe P, Guingnard B, Fletcher D, Maurette P, Sessler DI, et al. Remifentanil-induced postoperative hyperalgesia and its prevention with small-dose ketamine. Anesthesiology 2005; 103: 147-55.

8. Angst MS, Koppert W, Pahl I, Clark DJ, Schmelz M. Short-term infusion of the mu-opioid agonist remifentanil in humans causes hyperalgesia during withdrawal. Pain 2003; 106: 49-57.

9. Kissin I, Brown PT, Robinson CA, Bradly EL Jr. Acute tolerance in morphine analgesia: continuous infusion and single injection in rats. Anesthesiology 1991; 74: 166-71.

10. Kissin I, Lee SS, Arthur GR, Bradley EL Jr. Time coarse characteristics of acute tolerance development to continuously infused alfentanil in rats. Anesth Analg 1996; 83: 600-5.

11. Larcher A, Laulin JP, Celerier E, Le Moal M, Simonnet G. Acute tolerance associated with a single opiate administration: Involvement of N-methyl-D-aspartate-dependent pain facilitatory systems. Neuroscience 1998; 84: 583-9.

12. Cox BM, Ginsburg M, Osman OH. Acute tolerance to narcotic analgesic drugs in rats. Br J Pharmacol Chemother1968; 33: 245-56.

13. Kissin I, Brown PT, Bradly EL Jr. Magnitude of acute tolerance to opioids is not related to their potency. Anesthesiology 1991; 75: 8136.

14. Vinik HR, Kissin I. Rapid development of tolerance to analgesia during remifentanil infusion in humans. Anesth Analg 1998; 86: 1307-11.

15. Van Elstraete AC, Lebrun T, Sandefo I, Polin B. Ketamine does not decrease postopearative pain after remifentanil-based anesthesia for tonsillectomy in adults. Acta Anaesthesiol Scand 2004; 48: 756- 
60.

16. Ganne $\mathrm{O}$, Abisseror $\mathrm{M}$, Menault $\mathrm{P}$, Malhière $\mathrm{S}$, Chambost $\mathrm{V}$, Charpiat $\mathrm{B}$, et al. Low-dose ketamine failed to spare morphine after a remifentanil-based anesthesia for ear, nose and throat surgery. Eur J Anaesthesiol 2005; 22: 426-30.

17. Batra YK, Shamsah M, Al-Khasti MJ, Rawdhan HJ, Al-Qattan AR, Belani KG. Intraoperative small-dose ketamine does not reduce pain or analgesic consumption during perioperative opioid analgesia in children after tonsillectomy. Int J Clin Pharmacol Ther 2007; 45: 155-60.

18. Koppert W. Opioid-induced hyperalgesia. Pathophysiology and clinical relevance. Anaesthesist 2004; 53: 455-66.

19. McDonnell C, Zaarour C, Hull R, Thalayasingam P, Pehora C, Ahier J, et al. Pre-treatment with morphine does not prevent the development of remifentanil-induced hyperalgesia. Can J Anaesth 2008; 55 : 813-8.
20. Lenz H, Raeder J, Hoymork SC. Administration of fentanyl before remifentanil-based anaesthesia has no influence on post-operative pain or analgesic consumption. Acta Anaesthesiol Scand 2008; 52: 149-54.

21. Ling GS, Paul D, Simantov R, Pasternak GW. Differential development of acute tolerance to analgesia, respiratory depression, gastrointestinal transit and hormone release in a morphine infusion model. Life Sci 1989; 45: 1627-36.

22. Ho ST, Wang JJ, Liaw WJ, Lee HK, Lee SC. Surgical pain attenuates acute morphine tolerance in rats. Br J Anaesth 1999; 82: 112-6.

23. Rauf K, Vohra A, Fernandez-Jimenez P, O'Keeffe N, Forrest M. Remifentanil infusion in association with fentanyl-propofol anaesthesia in patients undergoing cardiac surgery: effects of morphine requirement and postoperative analgesia. Br J Anaesth 2005; 95: 611-5. 